\title{
Diagnosis of Pulmonary Embolism: Have We Reached Our Goal?
}

\author{
Antonio Palla Carlo Giuntini \\ Dipartimento Cardiotoracico, Università degli Studi di Pisa, Pisa, Italy
}

Pulmonary embolism (PE) is a common disease that may be fatal if untreated, while it may show a favorable course when promptly recognized and treated. Although clinicians have searched for objective tests to confirm or rule out the diagnosis, PE remains a challenging diagnostic problem since it is detected only at autopsy in about two thirds of cases, even in most recent published series.

In recent years, several diagnostic strategies have been introduced in clinical practice. In outpatients, the sequential use of D-dimer measurement, lower limb venous compression ultrasonography, clinical evaluation of the likelihood of PE and a correct interpretation of lung scan results make it possible to correctly treat more than $90 \%$ of patients with suspected PE and to safely not treat more than $99 \%$ [1]. In both out- and inpatients, the evaluation of clinical likelihood combined with a simple, practical reading of perfusion lung scintigraphy helps to restrict the need for angiography to a minority of patients [2]. Nevertheless, the demand for a single test that might accurately and noninvasively allow diagnosis of PE has remained high, more than for other diseases; lately, the hope of such a test seems finally to have become reality with the helical CT scan. Indeed, after the skeptical conclusion of Rathbun et al. [3] in their systematic review reported in 2000, evidence has been published that in patients with suspected PE, helical CT scan may be used efficaciously and safely as the primary test to detect and rule out PE [4]. A valid contribution to the exclusion of $\mathrm{PE}$ by helical $\mathrm{CT}$ scan is also given by Friera et al. [5] in their paper published in this issue of Respiration. In a prospective study including more than 200 patients, the authors give an elegant demonstration of the utility of a negative CT scan (when used as the only imaging method) in excluding clinically suspected PE. In their report, patients with clinically suspected PE, not otherwise anticoagulated and followed for a 3-month period of time, did not show venous thromboembolic events during the entire follow-up.

Though the aforementioned studies have raised widespread enthusiasm, we believe that the old issue concerning the entire diagnostic process and the following management of PE still remains far from having a definitive solution, and it deserves further consideration.

Firstly, the strategy for diagnosis varies among different centers according to the availability of one or more techniques that may integrate with each other. For instance, strong evidence has existed for a long time that perfusion lung scan, when normal, reliably excludes the diagnosis of PE without the necessity of further tests. Perfusion lung scan is objective, has a low cost and is easily repeatable, while helical CT is perhaps not cost-effective as a single test. Thanks to the same characteristics, perfusion lung scan may be used to control the efficacy of therapy after an adequate lapse of time, usually before hospital discharge. Is it cost-effective to perform such a control by helical CT? Is it feasible to use an instrument designed for emergencies for routine controls? As a matter of fact, it

\begin{tabular}{ll}
\hline KARGER & ( ) 2004 S. Karger AG, Basel \\
0025-7931/04/0711-0022\$21.00/0 \\
$\begin{array}{l}\text { Fax +4161306 12 34 } \\
\begin{array}{l}\text { E-Mail karger@karger.ch } \\
\text { www.karger.com }\end{array}\end{array}$ & $\begin{array}{l}\text { Accessible online at: } \\
\text { www.karger.com/res }\end{array}$
\end{tabular}

Dr. Antonio Palla

Dipartimento Cardiotoracico, Università di Pisa

Ospedale Cisanello, Via Paradisa, 2

IT-56126 Pisa (Italy)

Tel. +390509968 38, Fax +390505801 26, E-Mail a.palla@med.unipi.it 
occurs more and more often that patients first diagnosed with helical CT scan are later referred for pulmonary scintigraphy to determine whether or not they have improved.

Secondly, and most importantly, there is the worry that the wide availability of a diagnostic tool, even the most accurate (incidentally, papers on helical CT $[4,5]$ fail to provide information on the spectrum of $\mathrm{PE}$ on which they are reporting), might hide the true risk in the diagnosis of PE, i.e. its dramatic underdetection in about two thirds of patients who die before a diagnosis is made. Indeed, the recruitment of patients for diagnosis cannot be done by modern diagnostic techniques but only by an accurate clinical suspicion, which is prerequisite for a correct diagnosis. Physicians should become acquainted with the multiform clinical manifestations of PE and include this condition in the differential diagnosis whenever symptoms such as unexplained sudden-onset dyspnea, plain dyspnea and/or chest pain occur. There will never be a sophisticated test that could reduce the underdetection of $\mathrm{PE}$ without an accurate and prompt clinical suspicion.

We may conclude with Eisner [6] that 'although helical CT scan can be useful for the diagnosis of pulmonary embolism, the prior probability of PE must be considered in the diagnostic decision-making process'.

\section{References}

1 Perrier A, Bounameaux H: Diagnosis of pulmonary embolism in outpatients by sequential noninvasive tools. Semin Thromb Hemost 2001;27:25-32.

2 Miniati M, Pistolesi M, Marini C, Di Ricco G, Formichi B, Prediletto R, Allescia G, Tonelli L, Sostman HD, Giuntini C: Value of perfusion lung scan in the diagnosis of pulmonary embolism: Results of the Prospective Investigative Study of Acute Pulmonary Embolism Diagnosis (PISA-PED). Am J Respir Crit Care Med 1996;154:1387-1393.
3 Rathbun SW, Raskob GE, Whitsett TL: Sensitivity and specificity of helical computed tomography in the diagnosis of pulmonary embolism: A systematic review. Ann Intern Med 2000; 132:227-232.

4 van Strijen MJ, de Monje W, Schiereck J, Kieft GJ, Prins MH, Huisman MV, Pattynama PM: Advances in New Technologies Evaluating the Localisation of Pulmonary Embolism Study Group: Single-detector helical computed tomography as the primary diagnostic test in suspected pulmonary embolism: A multicenter clinical management study of 510 patients. Ann Intern Med 2003;138:307-314.
5 Friera A, Olivera MJ, Suárez C, Giménez N, Caballero P, and the Thromboembolic Study Group of 'La Princesa' Hospital: Clinical validity of negative helical computed tomography for clinical suspicion of pulmonary embolism. Respiration 2004;71:30-36.

6 Eisner MD: Before diagnostic testing for pulmonary embolism: Estimating the prior probability of disease. Am J Med 2003;114:232234. 